NBER WORKING PAPER SERIES

\title{
DO ON-LINE LABOR MARKET INTERMEDIARIES MATTER? THE IMPACT OF ALMALAUREA ON THE UNIVERSITY-TO-WORK TRANSITION
}

\author{
Manuel F. Bagues \\ Mauro Sylos Labini \\ Working Paper 13621 \\ http://www.nber.org/papers/w13621
NATIONAL BUREAU OF ECONOMIC RESEARCH
1050 Massachusetts Avenue
Cambridge, MA 02138
November 2007

We thank David Autor and Anne Polivka for very helpful comments. We also benefited from comments from participants at seminars at University of Oviedo, University of Bologna, 4th IZA/SOLE Transatlantic meeting, Bocconi University, S. Anna School of Advanced Studies, University of Alicante, 6th Villa Mondragone Workshop, XI Spring Meeting of Young Economists, and the NBER Conference on Labor Market Intermediation. The usual disclaimers apply. The empirical analysis would not have been possible without the data and help provided by Giovanni Seri at ISTAT (the Italian Statistical Office). The econometric analysis was carried out at the ADELE Laboratory. We are grateful to Michele Rostan for providing the data from the European Project "Careers after Higher Education: a European Research Study". Corresponding author Mauro Sylos Labini: m.syloslabini @imtlucca.it. The views expressed herein are those of the author(s) and do not necessarily reflect the views of the National Bureau of Economic Research.

(C) 2007 by Manuel F. Bagues and Mauro Sylos Labini. All rights reserved. Short sections of text, not to exceed two paragraphs, may be quoted without explicit permission provided that full credit, including (c) notice, is given to the source. 
Do On-Line Labor Market Intermediaries Matter? The Impact of AlmaLaurea on the University-to-Work Transition

Manuel F. Bagues and Mauro Sylos Labini

NBER Working Paper No. 13621

November 2007, September 2008

JEL No. J64,J68,O3

\begin{abstract}
This paper evaluates the impact of the availability of electronic labor markets on the university-to-work transition. In particular, we analyze the effect of the intermediation activity carried on by the inter-university consortium, AlmaLaurea, on graduates' labor market outcomes. The different timing of universities' enrollment in AlmaLaurea allows us to apply the difference-in-differences method to a repeated cross section data set. If the usual assumption concerning parallel outcomes holds, AlmaLaurea reduces the individual unemployment probability and improves matching quality. Interestingly, we also find that on-line intermediaries foster graduates' geographic mobility.
\end{abstract}

Manuel F. Bagues

Universidad Carlos III

C/ Madrid 126

28903 Getafe - Madrid

Spain

mfbagues@emp.uc3m.es

Mauro Sylos Labini

IMT Lucca Institute for Advanced Studies

Piazza S. Ponziano, 6

55100 Lucca

Italy

m.syloslabini@imtlucca.it 


\section{Introduction}

The internet and electronic technologies more generally have a great potential for changing the way employer-employee matches are made (Autor 2001). Since the mid 1990s there has been a well documented increase in the number of internet job boards and corporate web sites devoted to job applications, and in the shares of job seekers and recruiters using on-line resources. For example, according to Taleo Research, the incidence of Fortune 500 companies using their careers web site as a corporate job board increased from 29 percent in 1998 to 92 percent in 2002. Moreover, the importance of on-line technologies may be underestimated since the possible uses of the internet in job search are multifaceted and go well beyond viewing advertisements or posting résumés (Kuhn 2000). ${ }^{2}$

However, it has been extremely difficult to assess the impact of on-line technologies on labor market outcomes. The internet is believed to increase the amount of information available to recruiters and job seekers and at the same time to improve their ability to screen on-line applications and opportunities. Both aspects are likely to decrease the cost of job search and, therefore, to improve matching productivity (Pissarides 2000).

Nevertheless, it has also been noted that even if searching on-line has private individual benefits, it does not follow that the equilibrium effects on labor market outcomes are socially beneficial (Autor 2001). In a recent empirical investigation, Kuhn and Skuterud (2004) also find that - once individual observable characteristics are controlled for - internet seekers do not have shorter unemployment duration than other searchers and, in some specification, it may even be longer. As the authors acknowledge, these results may be contaminated by selection into internet job search on unobservables that are negatively correlated with employability. However, it is also possible that internet search is counterproductive at the individual level because of the negative signal it might send to employers. Workers may still use the internet, the authors argue, because it is very cheap and they are not aware of this drawback.

Therefore, despite their rapid diffusion, whether on-line electronic technologies are capable of increasing the overall efficiency with which workers and jobs are matched or, conversely, are merely cheaper substitutes for more traditional means (e.g. newspaper ads or face-to-face intermediation), is still an open issue.

This paper evaluates the impact of the availability of electronic labor markets on the university-to-work transition. In particular, we study the effects of a specific electronic

\footnotetext{
${ }^{2}$ In a recent report, the US Congressional Budget Office pointed out that "internet job searching may also have played a role in reducing the natural rate (of unemployment)" (CBO 2002).
} 
intermediary, the inter-university consortium AlmaLaurea, on graduates' unemployment, mobility, and matching quality. In a nutshell, AlmaLaurea collects and organizes on-line information concerning college graduates' curricula and, conditional on their permission, sells it to firms in electronic format. Hence, similar to other commercial job boards, it makes information about searching candidates available on-line. However, it also contains information on almost the entire universe of graduates from the institutions that it serves.

The present case study provides exceptional evidence on the effect of online labor market intermediaries for two main reasons: first, the impact of AlmaLaurea is observed during a time period when e-recruitment was almost non-existent in Italy. AlmaLaurea was founded in 1994 and, to the best of our knowledge, until 1999 there were no major internet job boards operating in Italy. Second, different timing of universities' enrolment in AlmaLaurea produces counterfactuals that allow us to tackle the problems faced by previous empirical investigations. Although today most Italian universities are members of AlmaLaurea, a smaller subset was in the consortium at the time our data were collected. We identify the average effect of AlmaLaurea on graduates from this initial subset - i.e. the ones that might have used its services - comparing the dynamics of their employment outcomes with those of graduates from universities that were not members. Hence, we aim at estimating the effect of the availability of electronic intermediaries, not the private benefits of using them.

Formally, we measure the effect of AlmaLaurea using the difference-in-differences (DID) approach applied to a repeated cross section data set. The data set is built by merging two distinct (but almost identical) surveys run by the Italian Statistical Office (ISTAT) on representative samples of two cohorts of university graduates interviewed three years after graduation. Given that AlmaLaurea intermediation activity only started in a subset of universities in the period between the graduation of the two cohorts, we split the sample in two distinct groups; graduates that completed their degree in a university that joined AlmaLaurea in 1996 and 1997 (the treatment group) and those that graduated from universities not members of AlmaLaurea during that period (the control group). The subtleties of envisaging participation of academic institutions in AlmaLaurea as a quasi-natural experiment are discussed in more depth below. Here, it suffices to say that, first, individual decisions concerning college enrolment were made before AlmaLaurea came into being; second, graduates and universities in the two groups are not statistically different in terms of observable characteristics; third, according to personal conversations with the consortium's director, initially membership in AlmaLaurea was fairly accidental and mostly based on informal relationships among a few faculties.

AlmaLaurea, as we discuss more thoroughly below, has a number of features that make it likely to be effective: first, it collects official information, which is partially disclose to firms, 
concerning also those individuals who decide not to post their résumés on-line. Second, it achieves very high enrolment rates from graduates. We conjecture that these features are likely to reduce adverse selection.

According to our most conservative estimate, AlmaLaurea decreases the probability of unemployment by about 1.6 percentage points and has a positive effect on wages, and two self-reported measures of job satisfaction. We also find that it fosters graduates' geographical mobility.

To check the robustness of the above findings, we test for pre-treatment parallel outcomes and find that graduates from the two groups of universities had similar employment dynamics prior to AlmaLaurea's operation. Our results might also be affected by the adverse consequence of AlmaLaurea for graduates from universities not members of the consortium. To control for this possibility, we build alternative treatment and control groups based on geographical proximity. We find no evidence of such a negative effect.

Our work is related to the growing number of studies that investigate the effect of the internet and electronic technologies on the labor market (Autor 2001; Freeman 2002). Kuhn and Skuterud (2004) study the impact of Internet job search on the probability of the unemployed finding a job. According to their analysis, there are no discernible differences between transition to employment of on-line and traditional searchers. They conclude that either on-line search is ineffective or that Internet job searchers are negatively selected. In a recent paper — methodologically similar to ours - Kroft and Pope (2008) exploit the uneven geographical expansion of the website Craigslist to assess the impact of on-line search on labor and housing markets efficiency. Although, consistently with Kuhn and Skuterud (2004), they find that on-line search had no effect on the unemployment rate, they did find that it lowered more traditional classified job advertisements in newspapers. Stevenson (2007) investigates the importance of on-line technologies on employed on-line job search and finds that in the United States state-level rise in Internet penetration is associated with state-level rise in employer-to-employer worker flows. In this paper, we focus on the impact of online search on a specific segment of the labor market, i.e. transition of university to work.

Our study is also useful for policy evaluation and formulation: the consortium $A l$ maLaurea is co-financed by the Italian Ministry of Education, therefore clear evidence on its effectiveness is useful for evaluating how public money is spent. ${ }^{3}$ Moreover, should $A l$ -

\footnotetext{
${ }^{3}$ Given that we do not know the magnitude of public funding invested, we are not able to measure whether AlmaLaurea is a worthwhile social investment; we can only measure whether students from AlmaLaurea member universities have benefited from it.
} 
maLaurea prove to be an effective institutional arrangement, other European countries might learn from its example, improving public policy aimed at facilitating the university-to-work transition.

The rest of the paper is organized as follows. Section 2 presents an overview of the university-to-work transition in Italy, provides an in depth description of the AlmaLaurea consortium, and briefly discusses the economics of on-line labor market intermediaries. Section 3 outlines the identification assumptions needed to make our empirical strategy valid. Section 4 describes of the data used in the analysis. Section 5 presents the main results. Sections 6 and 7 justify the validity of the results of our empirical approach, and Section 8 concludes.

\section{Background}

\subsection{University-to-work transition in Italy}

Labor market functioning is deeply affected by different kinds of information imperfections and asymmetries. The education-to-work transition is particularly exposed to these imperfections: first-time job seekers typically lack work experience and this negatively affects both their outlooks concerning employment opportunities and job characteristics, and employers' screening options.

In most countries unemployment rates are lower for university graduates than for the rest of labor force and highly educated people experience a smoother entry into working life (OECD 2007). As Table 1 shows, however, international comparisons depict the universityto-work transition in Italy as one of the most problematic cases among industrialized countries. ${ }^{4}$ There are three main possible explanation for this. First, there are frictions on the supply side: it might be that education provided by Italian universities is of such a poor standard that graduates are obliged to undertake further training, either formal or informal, before getting into work. Second, the slow transition rates may be due to labor demand characteristics: the Italian industrial structure, compared to that of other developed countries, is biased in favor of small firms and low tech industries that typically do not employ highly qualified workers. Third, there may be inefficiencies in the matching mechanisms caused by information imperfections and, possibly, by lack of intermediaries.

AlmaLaurea potentially improves labor market functioning for two reasons. First, it

\footnotetext{
${ }^{4}$ See also the data in Mannheim Centre for European Social Research (2002).
} 
Table 1: Employment rates of university graduates by age class - 2004

\begin{tabular}{lccc}
\hline \hline & \multicolumn{3}{c}{ Age Class } \\
Country & $25-29$ & $30-34$ & $35-39$ \\
Denmark & 79.7 & 87.7 & 91.2 \\
Finland & 84.4 & 86.7 & 87.9 \\
France & 80.1 & 85.0 & 87.5 \\
Greece & 72.2 & 85.5 & 87.9 \\
Italy & $\mathbf{5 8 . 0}$ & $\mathbf{8 1 . 9}$ & $\mathbf{8 9 . 4}$ \\
Spain & 76.3 & 85.9 & 86.7 \\
Sweden & 76.6 & 88.2 & 88.3 \\
UK & 90.5 & 98.1 & 90.1 \\
\hline
\end{tabular}

Source: Eurostat.

reduces search costs for both firms and workers by making accurate qualification, grade and study data readily available. Second, it may mitigate adverse selection by making it possible to compare searching students with others in their cohorts.

Universities are often active actors in labor market intermediation. For instance, most academic institutions set up and manage placement offices and, in some cases, their faculties establish informal ties with firms. ${ }^{5}$ However, when universities receive financial resources on a relatively egalitarian basis and their graduates' labor market performance does not affect their financial endowments, they may have little incentive to concern themselves with students' placement. In Italy before AlmaLaurea was established public universities were involved in minimal formal intermediation activity. ${ }^{6}$ Table 2 refers to 1995 graduates and for a selected sample of European countries displays the share of graduates who used the services of their institutions' placement office (first column) and the share of graduates who got their first job through this channel (second column). It can be seen that Italy ranks low, higher only than Germany, in both respects. ${ }^{7}$

\footnotetext{
${ }^{5}$ See Rebick (2000) for an insightful account of the Japanese case.

${ }^{6}$ There is anecdotal evidence that several departments on an informal basis provided unorganized paper based information on their graduates to recruiting companies.

${ }^{7}$ Percentages are calculated using the data set built by a European Community funded project under the Targeted Socio-Economic Research (TSER) "Careers after Higher Education: a European Research Study". See http://www. uni-kassel.de/wz1/tseregs.htm for details.
} 
Table 2: University graduates using university placement offices

\begin{tabular}{lcc}
\hline \hline Country & Utilization rates (\%) & Used to get the first job (\%) \\
Italy & 10.3 & 1.42 \\
Spain & 39.3 & 3.96 \\
France & 18.1 & 3.21 \\
United Kingdom & 37.6 & 6.61 \\
Germany & 6.6 & 0.54 \\
\hline
\end{tabular}

Notes: The relevant questions (asked in 1998 to graduates who obtained their degree between autumn 1994 and summer 1995$)$ were: (i) "How did you search for your first job after graduation?"; (ii) "Which method was most important for getting your first job after graduation?". Multiple options follow, among which "I enlisted the help of a careers/placement office in my higher education institution". The ratios displayed are computed respectively over graduates who have sought a job and over those graduates that have been employed at least once.

Source: Authors' calculation based on the data set produced by the Project funded by the European Community under the Targeted Socio-Economic Research (TSER) "Careers after Higher Education: a European Research Study".

Details on the project and downloadable material can be found at http://www.uni-kassel.de/wz1/tseregs.htm.

\subsection{AlmaLaurea}

AlmaLaurea was founded in 1994 and began on-line intermediation in 1995 at a time when, to the best of our knowledge, there were no other internet job boards in Italy. Monster and InfoJob, according to Nielsen/NetRatings the current most popular e-recruitment sites, started in 2001 and 2004 respectively. ${ }^{8}$

Initially run by the Statistical Observatory of the University of Bologna, AlmaLaurea currently managed by a consortium of 50 private and public universities with the support of the Italian Ministry of Education. Member universities pay a one-time association fee (ranging from 2582 to 5165 euros according to the size of the university) and an annual subscription fee for the collection and the insertion of new data in the AlmaLaurea database (4.96 euros for each student in the data base).

AlmaLaurea's institutional objectives are twofold. First, it provides member academic institutions with reliable information on their graduates. Second, it aims at facilitating graduates' labor market transition.

In terms of the first objective, AlmaLaurea manages a database that collects information on graduates drawing it from three distinct sources. First, academic institutions provide official data on grades, course durations, and degrees received for their alumni. Second, undergraduates provide several pieces of information including military service obligations,

\footnotetext{
${ }^{8}$ It ultimately proved impossible to establish with any precision the timing of the first Italian internet job-board. Nevertheless, according to personal communications with industry experts in the field the first was JobPilot, which was founded in 1999 and was acquired by Monster in 2005.
} 
Table 3: Evolution of AlmaLaurea

\begin{tabular}{|c|c|c|c|c|c|c|c|c|c|c|}
\hline & 1998 & 1999 & 2000 & 2001 & 2002 & 2003 & 2004 & 2005 & 2006 & 2007 \\
\hline Number of universities & 15 & 20 & 22 & 25 & 25 & 27 & 37 & 39 & 44 & 50 \\
\hline Share of graduates & .24 & .31 & .34 & .39 & .39 & .37 & .43 & .51 & .57 & .67 \\
\hline Number of $\mathrm{CV}$ in AlmaLaurea & 62745 & 105409 & 153843 & 213976 & 286345 & 367497 & 477282 & 624960 & 792575 & 900000 \\
\hline Number of CV sold & 3973 & 15999 & 115603 & 194635 & 164209 & 271364 & 389625 & - & - & - \\
\hline $\mathrm{CV}$ sold in the same region (share) & .55 & .72 & .50 & .37 & .35 & .30 & .30 & - & - & - \\
\hline
\end{tabular}

Source: Authors' calculation based on data provided by AlmaLaurea. "Share of graduates" refers to the share of graduates in AlmaLaurea universities with respect to the entire population of graduates in Italian universities. Data on CV sold for 2005 , 2006 , and 2007 are not available. Data for 2007 are estimates calculated in June 2007.

periods of study abroad, work experience, and a self-evaluation concerning foreign languages and computer skills. Finally, graduates have the option to upload and update their curricula on-line for up to three years after graduation. ${ }^{9}$ In accordance with Italian privacy law, only a subset of the information in the database can be disclosed to third parties. ${ }^{10}$

With respect to the second objective, AlmaLaurea manages a service that gives firm electronic access to graduates' CVs. The CV is an electronic file containing biographical information, age at graduation, university and high school grades, information on internships, experience abroad, postgraduate education, languages and computer skills, work experience, and work preferences (i.e. type of occupation desired, location, and contract preferred). Graduates may include additional information and a cover letter. ${ }^{11}$

The service is free for graduates. Firms and other institutions can browse individual curricula and observe populational aggregate information for free, are required to pay if they want to contact a particular graduate. The price ranges between 0.5 and 10 euros per CV, depending on the type of subscription and the number of curricula acquired. ${ }^{12}$

Table 3 provides an overview of AlmaLaurea's history and performance. It displays the number of universities enroled, the share of graduates from AlmaLaurea universities, the numbers of résumés available to firms, and sold by the consortium.

\footnotetext{
${ }^{9}$ Recently, the option was extended to 5 years.

${ }^{10}$ More information can be found on-line at http://www.almalaurea.it/eng/index.shtml

${ }^{11} \mathrm{~A}$ sample CV (in Italian) is available at: http://www . almalaurea.it/info/aiuto/aziende/esempio_cv.shtml.

${ }^{12}$ Firms can choose between self service or subscription. The so-called self-service involves payment of 50 euros, after which any number of CV can be acquired at the cost of 10 Euros per CV. Subscription allows a firm to prepay for a whole package of downloadable CVs, over a period of one year. The range is between $200 \mathrm{CVs}$ for around 500 euros up to $5000 \mathrm{CVs}$ for 2600 euros. More detailed information is available (in Italian) at http://www.almalaurea.it/info/condizioni/buono_ordine_abbonamenti.pdf.
} 


\subsection{AlmaLaurea and the economics of electronic labor markets}

The AlmaLaurea recruitment service turns out to be an insightful example concerning how on-line communication technologies - coupled with more traditional forms of intermediation - might ameliorate the way in which employers and employees match in the labor market. On-line labor market intermediaries are expected to decrease the search costs for both employers and employees. Standard search theory predicts that, everything being equal, this should lead to better matches. Conversely, the effects on unemployment duration are ambiguous. In fact, although Burdett and Ondrich (1985) suggest that it is unlikely, on-line technologies might induce both job seekers and employers to be more choosy and to increase their reservation wages and screening standards (Pissarides 2000). Finally, on-line labor market intermediaries are expected to weaken the constraints posed by geographical distance (Autor 2001). Consistently, in the AlmaLaurea case most graduates' curricula are bought by firms located in regions other than the one where the individual graduated (see Table 3).

On the other hand, a likely consequence of lower costs in distinct job search channels is that job seekers, ceteris paribus, will apply for more jobs. And when employers perceive such excess application to be a problem, adverse selection is likely to undermine the effectiveness of cheap search methods (Autor 2001).

With the exception of time required to update personal information, AlmaLaurea is completely free for students and therefore is potentially exposed to the adverse selection problem referred to above: employers might expect that individuals who upload and update their résumés on-line are somehow negatively selected. However, AlmaLaurea's organizational features are likely to make its intermediation activity less exposed to the above risk for two reasons.

First, as explained above, some pieces of the information contained in AlmaLaurea data set concern the entire graduates population and are provided directly by academic institutions. This information is organized by AlmaLaurea and made freely available on-line at its website. ${ }^{13}$ For every member university and degree, the website provides information on average grades, share of students that completed their degree on time, and the share of individuals that studied abroad within a EU subsidized program. Therefore, employers who purchase a CV should be able to identify differences between the selected job seeker and the entire graduate population which considerably reduces the adverse selection problem.

Second, academic institutions that joined AlmaLaurea are able to enroll the vast ma-

\footnotetext{
${ }^{13}$ See (in Italian) http://www.almalaurea.it/cgi-php/aziende/profilo/profilo.php.
} 
jority of their graduates. For instance, more than $92 \%$ of 1998 graduates updated their CVs on-line at least once. High participation rates have been very effective in building a good reputation for the serve, and make adverse selection unlikely. To sum up, we expect that AlmaLaurea's particular organizational features protect it from the disadvantages of on-line labor markets.

\section{The empirical strategy}

The basic goal of this paper is to evaluate the impact of a treatment, i.e. the availability of on-line labor market intermediaries, on an array of labor market outcomes, i.e. the probability of being unemployed, mobility, and matching quality. This section formalizes and explicitly discusses our empirical approach and outlines the strategies employed to assess its validity.

One of the most serious empirical problems that arises in assessing the impact of on-line intermediaries is that job seekers and firms typically self select in the adoption of on-line technologies. It is therefore difficult to identify to what extent the correlation between their use and labor market outcomes stems from the technology itself and to what extent it stems from some important and difficult to measure individual characteristics.

In this paper we can rely on a transparent exogenous source of variation, i.e. the timing of universities' enrolment in AlmaLaurea. This heterogeneity allows to apply the DID method to a repeated cross-section data set. This helps to overcome the above mentioned problem.

The simple DID framework can be described as follows. The causal effect of a treatment on an outcome is defined as the difference between two potential outcomes (Rubin 1974; Heckman 1990). Of course, it is impossible to observe such an effect for a given individual. However, it is possible to identify an average effect if the population of interest is observed in at least two distinct time periods, if only a fraction of the population is exposed to treatment, and if we assume parallel paths over time for treated and controls. The main intuition is that, under this design, an untreated group of the population is used to identify time variation in the outcome that is not due to treatment exposure.

More formally, each individual $i$ belongs to one group, $G_{i} \in\{0,1\}$, where for convenience group 1 is the treatment group and 0 the control one. Moreover, individual $i$ is observed only in time period $T_{i} \in\{0,1\}$. Let $I_{i}=G_{i} \cdot T_{i}$ denote an indicator for the actual subministration of treatment. ${ }^{14} Y_{i}^{N}(t)$ and $Y_{i}^{I}(t)$ represent two potential outcomes: respectively,

\footnotetext{
${ }^{14}$ Note that in our simple setting $I_{i}$ assumes the value 1 only for the treatment group $\left(G_{i}=1\right)$ in the post
} 
that achieved by $i$ at time $t$ if not treated and that achieved if treated before $t$.

The fundamental problem in identifying the treatment effect on individual $i$, defined as $Y_{i}^{I}(t)-Y_{i}^{N}(t)$, is that for any particular individual, it is not possible to observe both potential outcomes. What we do observe is the realized outcome, which can be written as $Y_{i}(t)=Y_{i}^{I}(t) \cdot I_{i}+Y_{i}^{N}(t) \cdot\left(1-I_{i}\right)$.

If it is assumed that

$$
E\left[Y_{i}^{N}(1)-Y_{i}^{N}(0) \mid G_{i}=1\right]=E\left[Y_{i}^{N}(1)-Y^{N}(0) \mid G_{i}=0\right],
$$

then, it easily follows that

$$
\begin{aligned}
E\left[Y_{i}^{I}(1)-Y_{i}^{N}(1) \mid G_{i}=1\right]= & E\left[Y_{i}(1) \mid G_{i}=1\right]-E\left[Y_{i}(0) \mid G_{i}=1\right] \\
& -\left\{E\left[Y_{i}(1) \mid G_{i}=0\right]-E\left[Y_{i}(0) \mid G_{i}=0\right]\right\}
\end{aligned}
$$

In other words, if the average outcomes for the treatment and control groups had parallel paths over time in the absence of treatment, then the so-called average treatment effect on the treated (ATT) can be expressed as something whose sample counterpart is observable, i.e. as the average variation of the treatment group purged by the average variation of the control group.

Hence in the present study, it is assumed that in absence of AlmaLaurea the average occupational outcomes of graduates from early joining universities (hereafter AlmaLaurea universities) would have followed the same dynamics as those of graduates from universities that either joined later or did not join (hereafter non-AlmaLaurea universities). Thus the average effect of AlmaLaurea is simply obtained by subtracting the dynamics of the graduates of the control group from the dynamics of those in the treatment group.

The above estimator is easily obtained as

$$
Y_{i}=\mu+\gamma \cdot G_{i}+\delta \cdot T_{i}+\alpha \cdot\left(G_{i} \cdot T_{i}\right)+u_{i}
$$

where $\alpha$ is the ATT and the assumption stated in equation 1 is equivalent to mean independence.

The validity of our approach faces a number of threats. As far as the so-called internal validity is concerned, i.e. the causal effect within the context of the study, there are two main problems. ${ }^{15}$ First, the compositional effect: the use of repeated cross-sections is only valid

treatment period $\left(T_{i}=1\right)$.

${ }^{15}$ See Meyer (1995) for a comprehensive discussion of internal validity in this framework. 
when the composition of the target population does not change between the two periods, i.e. $u_{i} \perp T_{i} \mid G_{i}$. Given that individual decisions concerning college enrolment were taken before the existence of AlmaLaurea, we can presume that, in our case, this problem is not very severe. Nevertheless, following standard practice, we shall test whether the means of relevant characteristics of the population within each group did change unevenly between the pre-treatment and the post-treatment periods.

Second, the assumption of parallel dynamics in the absence of treatment between the two groups (equation 1) turns out to be strong. It is, in fact, possible that the two groups have different trends for reasons other than treatment. However, if non-parallel dynamics are due to observables, we can overcome the problem by including covariates. This analysis, as we discuss in detail in Section 4, relies on a large array of individual and university covariates. Nevertheless, if the dynamics of the outcome variables of the two groups are affected by unobservables, identification breaks down. ${ }^{16}$ In Section 6 , we try to overcome this important problem using data for an additional pre-treatment period in order to test for non-parallel paths between the treatment and control groups before treatment.

Another issue concerns the unit of analysis of our ATT. It could be that AlmaLaurea might not be an appropriate individual level treatment since member institutions are enrolled at once, and there are possibly important interactions among each university's students. If, for instance, the impact of AlmaLaurea on a given student depends on the characteristics of students in her cohort, we are measuring the effect on university rather than the individual graduate employment performance. Although in the present study we model AlmaLaurea as an individual level treatment, in future research we aim to investigate the possibility of within university spillovers.

Similarly, to be valid, the DID approach assumes no interactions among the agents in the treatment and control groups. If, for example, AlmaLaurea graduates improved occupational outcomes harm non-AlmaLaurea graduates, our estimates have very different implications, especially in terms of informing policy. In Section 7, we try to assess this problem identifying additional control and treatment groups which include only graduates from those universities that are located in the same geographical region.

Finally, in order to generalize the results to different individuals and contexts, external validity is important. It is possible that AlmaLaurea would not have had an effect for graduates from those universities that chose not to join. This would also explain why they did not join. However, we do not think this is a major problem since, as mentioned in the intro-

\footnotetext{
${ }^{16}$ Given that decisions to enrol in AlmaLaurea are made by universities, we are mostly concerned with university unobservables.
} 
Table 4: Universities enrolled in AlmaLaurea

\begin{tabular}{cl}
\hline \hline 1994 & University of Bologna starts collecting electronic data concerning its graduates \\
1995 & University of Bologna starts selling data \\
1996 & University of Modena-Reggio Emilia, Ferrara, Parma, and Florence start selling data \\
1997 & University of Catania, Trieste, Udine, Messina, Chieti, Trento, Molise, \\
& and Venice School of Architecture start selling data \\
August 1998 & University of Turin and Eastern Piedmont start selling data \\
\hline
\end{tabular}

Note: The Venice School of Architecture started selling data on January 1. For consistency it is included in 1997 group. The Universities of Siena and Lecce joined in 1997, but did not start to sell CVs until 1999 and 2003 respectively. All the information is available on the AlmaLaurea web site.

duction, membership tended to be accidental, at least during the first years. Nevertheless, below we test whether the observable characteristics of the universities in the two groups differ significantly.

\section{The data}

Our data on graduates are drawn from two almost identical surveys - Indagine Inserimento Professionale Laureati (Survey on University-to-Work Transition) in 1998 and 2001 of individuals who graduated in 1995 and 1998 respectively. ${ }^{17}$

To implement the econometric approach described in Section 3 we include in our main treatment group those individuals graduating from universities that joined AlmaLaurea in 1996 and 1997. As shown in Table 4, this includes the universities of Modena-Reggio Emilia, Ferrara, Parma, Florence, Catania, Trieste, Udine, Messina, Chieti, Trento, Molise and Venice School of Architecture. Students in the treatment group account for about 18 per cent of the sample (see Table 5).

In Section 5.2, we exploit an additional source of variation. As shown in Table 4, the Universities of Turin and Eastern Piedmont start selling graduates CVs only after August 1998. Thus, we used graduates from these universities as an additional treatment group in a DID setting in which the "before and after" are the time of graduation before and after August 1998 and only graduates from 1998 are considered. ${ }^{18}$

\footnotetext{
${ }^{17}$ The publicly available micro-data do not include information concerning from which university the surveyed individual graduated. Therefore, we carried out the analysis at the ADELE ISTAT laboratory in Rome.

${ }^{18}$ In Italy graduates can complete their degree at different times in the same academic year, depending on
} 
Unfortunately, ISTAT does not provide information concerning the month of graduation for 1995 graduates. Therefore, graduates from Bologna are not considered in the analysis. ${ }^{19}$

The ISTAT target samples consist of 25,716 individuals in 1998 and 36,373 individuals in 2001. They represent respectively $25 \%$ and $28.1 \%$ of the total population of Italian university graduates. The response were $64.7 \%$ and $53.3 \%$ for a total of 17,326 and 20,844 respondents. ${ }^{20}$ After eliminating individuals that did not respond to the question concerning their employment status, those with missing values for key variables, and graduates from Bologna, Turin and Eastern Piedmont, we are left with 15,282 and 18,181 observations respectively. In both years the sample is stratified according to sex, university and university degree and in the analysis below all estimations are performed using stratification weights.

The surveys collect information on (i) school and university curricula, (ii) labor market experience, and (iii) demographic and social backgrounds of graduates. Table 5 presents summary statistics for the key variables. In the analysis below, individual level right-hand variables are grouped into two subsets. The first includes characteristics that are predetermined with respect to college efforts and outcomes: sex, age, high school grades, 14 dummies for high school type, 1 dummy for having two university degree, 5 dummies for each parent's level of education, 104 dummies for province of residence before college enrolment, and 345 dummies for departments (university*field of study). The second contains indicators related to college curricula that could - at least potentially-be influenced by AlmaLaurea: university grade and number of years to graduation.

As Table 5 shows, with the exception only of the share of women which increased for both groups, the remaining variables show no notable variations within groups over time. Moreover, control and treatment groups present very similar characteristics for both years, reducing the possibilities of major interactions (beyond the treatment itself) at the individual level between being enroled in a college member of AlmaLaurea and graduating in 1998.

In order to control for observable variations in academic institution quality, we use data on university characteristics provided by ISTAT in its annual Lo Stato dell'Universitá

when they finish their dissertation.

${ }^{19}$ Bologna is also a very special case, the most "self-selected" one, given that it is the university where AlmaLaurea get started. However, results do not change qualitatively whether we include Bologna graduates in the control group or the treatment group.

${ }^{20}$ Differences in response rates probably stem from the different interviewing techniques in the surveys: in 1998 ISTAT mailed paper-based questionnaires, while in 2001 the CATI (Computer Assisted Telephone Interview) was used. In principle, this change should affect universities in a homogenous way and therefore it should not represent a major problem for our analysis. 
Table 5: Sample design and means of key variables

\begin{tabular}{lccc}
\hline \hline 1998 Survey: & All & AlmaLaurea & Non-AlmaLaurea \\
Number of graduates & & & \\
Weighted share & 15282 & 3512 & 11770 \\
2001 Survey: & & .188 & .812 \\
Number of graduates & 18181 & 3515 & 14666 \\
Weighted share & & .183 & .817 \\
\hline Means of selected sample characteristics in 1998: & All & AlmaLaurea & Non-AlmaLaurea \\
Share of female & .527 & & \\
& $(.004)$ & $(.010)$ & .527 \\
Age & 27.45 & 27.61 & $(.005)$ \\
& $(.038)$ & $(.086)$ & $(.042)$ \\
High school grade & 48.38 & 47.87 & 48.49 \\
Means of selected sample characteristics in 2001: & $(.066)$ & $(.151)$ & $(.074)$ \\
Share of female & & & .548 \\
Age & .551 & .567 & $(.004)$ \\
High school grade & $(.004)$ & $(.009)$ & 27.45 \\
& 27.47 & 27.55 & $(.031)$ \\
& $(.028)$ & $(.063)$ & 49.04 \\
& 48.96 & 48.62 & $(.064)$ \\
\hline
\end{tabular}

Notes: Standard errors in parentheses. Shares, means and standard errors are computed with stratification weights. High school grades range from 36 to 60 . Only individuals that responded to the question about employment status are considered. 
Table 6: Universities characteristics

\begin{tabular}{lccc}
\hline \hline & All & AlmaLaurea & Non- AlmaLaurea \\
Universities in 1995 & 59 & 12 & 47 \\
Number of universities & & & \\
& 23946 & 22033 & 24434 \\
Average number of students & $(3742)$ & $(4569)$ & $(4568)$ \\
& 31.09 & 26.27 & 32.32 \\
Average number of students per professor & $(2.59)$ & $(2.53)$ & $(3.17)$ \\
& .288 & .278 & .291 \\
Average share of delayed students & $(.010)$ & $(.026)$ & $(.011)$ \\
& & & \\
Universities in 1998 & & & \\
Number of universities & 61 & 12 & 49 \\
& & & \\
Average number of students & 25473 & 24134 & 25801 \\
& $(3875)$ & $(5096)$ & $(4679)$ \\
Average number of students per professor & 31.82 & 26.50 & 33.12 \\
& $(2.36)$ & $(3.15)$ & $(2.82)$ \\
Average share of delayed students & .362 & .396 & .354 \\
& $(.011)$ & $(.029)$ & $(.012)$ \\
\hline
\end{tabular}

Notes: Averages are computed at university level. Standard errors in parentheses

(University Indicators), for the academic years 1991-98. In particular, we collect information at the level of the individual university, on numbers of students, professors, and delayed students. $^{21}$ Table 6 shows that universities in the treatment group enrol fewer students per professor than the universities in the control group. The difference, however, is not statistically significant. The two groups have very similar average rates of delayed students. Both indicators are generally considered proxies for university teaching quality. ${ }^{22}$ Note, also, that the share of delayed students increased in both groups, but the increase is steeper for the treatment group. In terms of overall number of students, the two groups of universities have very similar averages.

Finally, to control for major economic shocks that may affect graduate labor market

\footnotetext{
${ }^{21}$ In Italy most students graduate after the official deadline.

${ }^{22}$ As discussed in Bagues et al. (2008) both indicators have drawbacks in a system such as the Italian one where most universities cannot restrict entry and therefore the number of students per professor depends, among other things, on demand.
} 
performance, we collect province ${ }^{23}$ level information on per capita Gross Domestic Product (GDP) and unemployment rates.

The present study considers three basic outcome variables measured three years after graduation: occupational status, which takes the value 1 if an individual is unemployed, and 0 otherwise; ${ }^{24}$ regional mobility, which takes the value 1 if the individual resides in a different region from the one where she graduated; ${ }^{25}$ and wage, measured as net monthly wage expressed in euros and self reported by the interviewed. We also consider two additional proxies for matching productivity. The first is for the perceived level of adequacy of the knowledge acquired at university with respect to the content of the present job. The second is related to the perceived stability of the job. Both variables are self reported and take values from 1 , not at all satisfied, to 4 , very satisfied.

\section{The impact of AlmaLaurea}

\subsection{Universities that joined in 1996 and 1997}

A first picture of the impact of AlmaLaurea is obtained by comparing time differences in means of key outcomes within the two groups (treatment and control). Table 7 shows that unemployment rates decreased sharply from 1998 to 2001 for the whole target population. ${ }^{26}$ Moreover, and most importantly for the present study, occupational status improved the most for those in the treated group: the rate of unemployment decreased about 3.5 points more than in the control group. Note also that the ranking between the two groups reverses. This means that the same qualitative result would be obtained if we used changes in employment logs as outcome variables.

For mobility, rates remained stable for AlmaLaurea students, and decreased for nonAlmaLaurea ones. Hence, for graduates in the treatment group regional mobility increased

\footnotetext{
${ }^{23}$ Italy is composed by 104 provinces which correspond approximately to US counties.

${ }^{24}$ Following standard definitions, we consider unemployed to be those individuals that declare not to having worked during the week before the interview and to be searching for a job.

${ }^{25}$ Italy is composed of 20 regions.

${ }^{26}$ Italian labor market conditions improved substantially between 1998 and 2001. According to ISTAT, standardized unemployment rates for the entire population were 11.7 in 1998 and 9.4 in 2001. The change was from 12.8 to 9.8 for university graduates aged between 25 and 39. It could be that our figures display a steeper decrease because individuals in the sample are younger and because of the changes made to the survey technique mentioned above.
} 
Table 7: Unemployment, mobility and wages by year and AlmaLaurea

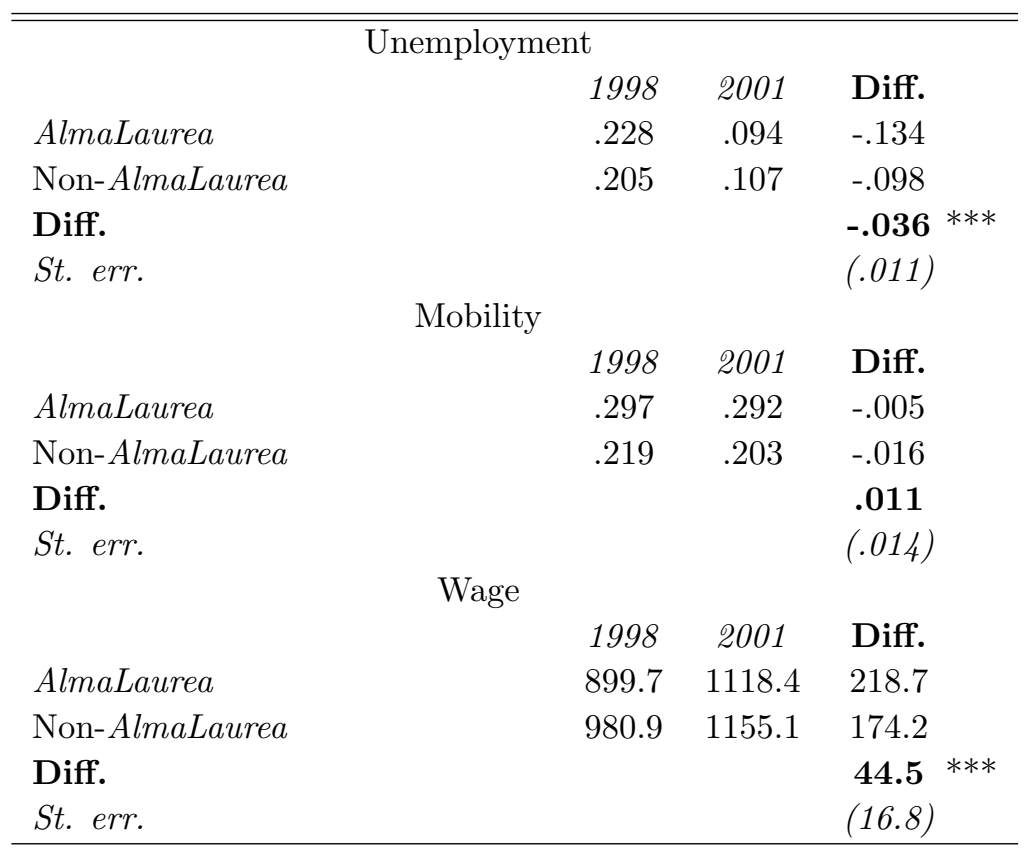

Notes: Unemployment rates are computed using stratification weights. We consider unemployed to be those individuals that did not work during the week before the interview who were looking for a job. Average gross monthly wages are expressed in euros and are calculated for the 20,838 individuals that provide this information. The bold differences are the results of a DID estimation, where

Diff $=\left(Y_{A l m a}^{01}-Y_{A l m a}^{98}\right)-\left(Y_{n o n A l m a}^{01}-Y_{\text {non Alma }}^{98}\right)$. In parentheses are robust standard errors of regressions of the dependent variables on dummies for year, belonging to AlmaLaurea, and their interaction. 
Table 8: The effect of AlmaLaurea on unemployment probability

\begin{tabular}{|c|c|c|c|c|}
\hline & (1) & $(2)$ & (3) & (4) \\
\hline AlmaLaurea & $-.020^{* *}(.008)$ & $-.021^{* *} \quad(.008)$ & $-.021^{* *}(.008)$ & $-.016^{*} \quad(.008)$ \\
\hline 2001 & $-.101^{* * *}(.013)$ & $-.103^{* * *}(.013)$ & $-.099^{* * *} \quad(.013)$ & $-.073^{* * *} \quad(.013)$ \\
\hline Female & $.060^{* * *}(.006)$ & $.061^{* * *} \quad(.005)$ & $.061^{* * *}(.005)$ & $-.061^{* * *} \quad(.005)$ \\
\hline Age & $-.002^{* *}(.001)$ & $-.004^{* * *}(.001)$ & $-.004^{* * *}(.001)$ & $-.004^{* * *} \quad(.001)$ \\
\hline High school grade & $-.002^{* * *}(.0003)$ & $-.001^{* * *}(.0004)$ & $-.001^{* * *}(.0004)$ & $-.001^{* * *} \quad(.0004)$ \\
\hline University grade & & $-.001^{* *} \quad(.005)$ & $-.001^{* *} \quad(.001)$ & $-.001^{* *} \quad(.0006)$ \\
\hline Students per faculty & & & $-.002^{* * *}(.001)$ & $-.002^{* * *} \quad(.001)$ \\
\hline Share of delayed students & & & $(.073)$ & $(.077)$ \\
\hline GDP & & & & $-.001^{* * *} \quad(.0003)$ \\
\hline Provincial unemployment & & & & $.009^{* * *} \quad(.003)$ \\
\hline Dummies on year delay & & YES & YES & YES \\
\hline R-squared & 0.147 & 0.147 & 0.149 & 0.150 \\
\hline Obs. & 33463 & 33463 & 33463 & 33463 \\
\hline
\end{tabular}

Notes: The results of four different specifications of a linear probability model are displayed. The dependent variable assumes the value 1 if the individual declares not to be working and to be searching, 0 otherwise. All specifications include university*department fixed effects, 14 dummies for high school type, 11 dummies for having another university degree, 5 dummies for each parent's level of education, 104 dummies for province of residence before university enrolment. Column 1 includes only predetermined individual control, column 2 considers all individual controls, column 3 incorporates time variant university characteristics, and column 4 includes Provincial GDP and unemployment rate. Robust Standard Errors in parenthesis. All regression are clustered at region*degree*year.

* significant at $10 \%{ }^{* *}$ significant at $5 \%$; ${ }^{* * *}$ significant at $1 \%$.

by about 1 point relatively to graduates in the control group. However, this difference is not statistically different from zero. Note also that graduates in the treatment group are more mobile than those in the control group. Finally, in terms of matching quality, monthly wages increased by some 44 euros more for AlmaLaurea graduates than for the control group.

To interpret the above results as being the sole effect of AlmaLaurea, involves assuming that in the absence of the treatment the averages of the two groups would have experienced the same variation (equation 1). This is a strong restriction when treatment (i.e. graduating from a university enroled in AlmaLaurea) is not randomly assigned across individuals. In the remaining part the paper we use the approaches outlined in Section 3 to assess the extent to which the observed changes may be interpreted as the effect of AlmaLaurea.

The basic identification assumption of the DID method (equation 1) may be too stringent if treatment and control groups are unbalanced in covariates that are thought to be associated with the dynamics of the outcome variable. To begin with, we follow the traditional way to accommodate this problem and introduce a linear set of controls $X_{i}$ in equation 3, which then becomes:

$$
Y_{i}=\mu+\beta \cdot X_{i}+\gamma \cdot G_{i}+\delta \cdot T_{i}+\alpha \cdot\left(G_{i} \cdot T_{i}\right)+u_{i},
$$


Table 9: The effect of AlmaLaurea on mobility

\begin{tabular}{|c|c|c|c|c|c|c|c|}
\hline \multirow[b]{2}{*}{ AlmaLaurea } & \multirow{2}{*}{$\begin{array}{c}(\mathbf{1}) \\
.024^{* *}(.011)\end{array}$} & \multicolumn{2}{|c|}{$(2)$} & \multicolumn{2}{|c|}{ (3) } & \multicolumn{2}{|c|}{$(4)$} \\
\hline & & $.024^{* *}$ & $(.012)$ & $.027^{* *}$ & $(.012)$ & $.024^{* *}$ & $(.012)$ \\
\hline 2001 & $-.008 \quad(.007)$ & -.008 & $(.007)$ & .007 & $(.008)$ & -.009 & $(.011)$ \\
\hline Female & $-.022^{* * *}(.004)$ & $-.022^{* * *}$ & $(.005)$ & $-.022^{* * *}$ & $(.005)$ & $-.022^{* * *}$ & $(.005)$ \\
\hline Age & $-.001^{* *}(.001)$ & .0004 & $(.0006)$ & .0003 & $(.0006)$ & .0002 & $(.0006)$ \\
\hline High school grade & $.001^{* *}(.0003)$ & .0002 & $(.0003)$ & .0003 & $(.0003)$ & .0004 & $(.0003)$ \\
\hline University grade & & .0003 & $(.0006)$ & 0003 & $(.0006)$ & .0001 & $(.0006)$ \\
\hline Students per faculty & & & & .001 & $(.001)$ & -.001 & $(.001)$ \\
\hline Share of delayed students & & & & $-.209^{* * *}$ & $(.001)$ & $-.179^{* *}$ & $(.077)$ \\
\hline GDP & & & & & & -.0005 & $(.001)$ \\
\hline Provincial unemployment & & & & & & -.005 & $(.004)$ \\
\hline Dummies on year delay & & \multicolumn{2}{|c|}{ YES } & \multicolumn{2}{|c|}{ YES } & \multicolumn{2}{|c|}{ YES } \\
\hline R-squared & 0.282 & \multicolumn{2}{|c|}{0.283} & \multicolumn{2}{|c|}{0.283} & \multicolumn{2}{|c|}{0.283} \\
\hline Obs. & 33463 & \multicolumn{2}{|c|}{33463} & \multicolumn{2}{|c|}{33463} & \multicolumn{2}{|c|}{33463} \\
\hline
\end{tabular}

Notes: The results of four different specifications of a linear probability model are displayed. The dependent variable assumes the value 1 if an individual resides in a different region from one where she attended university, and 0 otherwise. All specifications include university*department fixed effects, 14 dummies for high school type, 11 dummies for having another university degree, 5 dummies for each parent's level of education, 104 dummies for province of residence before university enrolment. Column 1 includes only predetermined individual controls, column 2 considers all individual controls, column 3 incorporates time variant university characteristics, and column 4 includes Provincial GDP and unemployment rate. Robust Standard Errors in parentheses. All regression are clustered at region*degree*year.

${ }^{*}$ significant at $10 \%{ }^{* *}$ significant at $5 \% ;{ }^{* * *}$ significant at $1 \%$.

Tables 8, 9, and 10 report ordinary least square (OLS) coefficients of the above equation where the outcome is respectively unemployment, mobility and log wages. All standard errors are corrected for the non-independence of employment outcomes of individuals graduating in the same region, degree, and year. ${ }^{27}$ The analysis is structured along the classification described in Section 4 - hence four specifications are displayed: column 1 includes individual characteristics predetermined before university entry; column 2 presents also potentially endogenous individual controls; column 3 incorporates time-variant university characteristics; column 4 displays the results of a regression that includes province unemployment and GDP per capita. Note that all specifications include university time department dummies.

Table 8 shows that, conditional on individual characteristics, if a university decides to affiliate to AlmaLaurea the probability that its graduates are unemployed three years after graduation significantly decreases by about 2 points. Potentially endogenous individual regressors (column 2) and university controls (column 3) do not affect significantly our results. Conversely, controlling for provincial unemployment rates and GDP (column 4) reduces the

\footnotetext{
${ }^{27}$ If we cluster standard errors at university level, most of the coefficients are not statistically significant at the $10 \%$ level.
} 
magnitude of the coefficient to about 1.6 points and also its statistical significance. However, the coefficient is still statistically significant at the 10 percent level. Quantitatively, this implies that, out of the 23,688 individuals that graduated from a member university in 1998, 379 graduates were out of unemployment as a consequence of AlmaLaurea adoption. Although we do not have direct evidence on the extent to which AlmaLaurea crowded out other search channels, this finding is plausible if one observes the high number of curricula sold by the consortium displayed in Table 3 .

Table 9 shows that also regional mobility rates have different dynamics for graduates in AlmaLaurea universities: depending on the controls used, AlmaLaurea has a positive and statistically significant effect on mobility, ranging from 2.3 to 2.8 points: ${ }^{28}$ about 570 individuals that without the consortium would have been resident in the region where they graduated, moved to a different one.

As mentioned, lower search costs are also expected to improve the quality of labor market matches. Table 10 shows that according to our analysis AlmaLaurea significantly increases monthly wages by about 3 percent. ${ }^{29}$ Taking as a reference the average wage, this implies that working graduates made about 35 more euros per month. We also find that AlmaLaurea increases graduates' satisfaction with the adequacy of the knowledge acquired at university, and job stability. ${ }^{30}$

\subsection{Universities that joined in 1998}

The above findings may be driven by time varying omitted university characteristics. To investigate whether this is the case, in this section, we exploit an additional source of exogenous variation. The Universities of Turin and Eastern Piedmont joined AlmaLaurea in August 1998 and hence sold résumés on-line only for those 1998 graduates that completed their degree after that date. In our alternative DID setting the new treatment group is composed of graduates from these two universities with the before and after being graduation after August 1998. In this specification only 1998 data are considered and dummies for month of graduation are included. As Table 11 shows, AlmaLaurea significantly decrease unemployment probability by about 2.5 points, which is a similar magnitude to the effect

\footnotetext{
${ }^{28}$ Similar results are obtained if we consider provincial mobility.

${ }^{29}$ This result needs to be interpreted with caution because of the possible different composition of the two samples. In fact wage regressions are run only for those individuals who are employed.

${ }^{30}$ Results are not reported but are available upon request by the authors.
} 
Table 10: The effect of AlmaLaurea on wages

\begin{tabular}{|c|c|c|c|c|}
\hline & (1) & $(2)$ & (3) & (4) \\
\hline AlmaLaurea & $.034^{*}(.017)$ & $.036^{* *} \quad(.018)$ & $(.018)$ & $.031^{*} \quad(.018)$ \\
\hline 2001 & $.222^{* * *}(.015)$ & $.227^{* * *} \quad(.015)$ & $.227^{* * *} \quad(.016)$ & $.201^{* * *} \quad(.020)$ \\
\hline Female & $-.153^{* * *}(.008)$ & $-.157^{* * *}(.008)$ & $-.158^{* * *}(.008)$ & $-.158^{* * *} \quad(.008)$ \\
\hline Age & $.013^{* * *}(.002)$ & $.017^{* * *} \quad(.001)$ & $.017^{* * *}(.002)$ & $.017^{* * *} \quad(.002)$ \\
\hline High school grade & $.005^{* * *}(.0005)$ & $.003^{* * *} \quad(.0006)$ & $.003^{* * *} \quad(.0006)$ & $.003^{* * *}(.0006)$ \\
\hline University grade & & $.005^{* * *} \quad(.0008)$ & $.005^{* * *} \quad(.0008)$ & $.005^{* * *}(.0008)$ \\
\hline Students per faculty & & & $.003^{*} \quad(.001)$ & $.002 \quad(.001)$ \\
\hline Share of delayed students & & & $(.100)$ & $(.102)$ \\
\hline GDP & & & & $.002^{* * *} \quad(.0005)$ \\
\hline Provincial unemployment & & & & $-.011^{* *} \quad(.005)$ \\
\hline Dummies on year delay & & YES & YES & YES \\
\hline R-squared & 0.252 & 0.259 & 0.259 & 0.260 \\
\hline Obs. & 20838 & 20838 & 20838 & 20838 \\
\hline
\end{tabular}

Notes: The results of three different specifications of a OLS model are displayed. The dependent variable is the logarithm of monthly net wages. All specifications include university*department fixed effects, 14 dummies for high school type, 11 dummies for having another university degree, 5 dummies for each parent's level of education, 104 dummies for province of residence before university enrolment. Column 1 includes only predetermined individual control, column 2 considers all individual controls, column 3 incorporates time variant universities characteristics, column 4 includes provincial GDP and provincial unemployment rates. Robust Standard Errors in parentheses. All regression are clustered at region*degree* year.

* significant at $10 \% ;{ }^{* *}$ significant at $5 \% ;{ }^{* *}$ significant at $1 \%$.

achieved above. However, there is no significant effect on either mobility or wages.

\section{Unparallel outcomes}

Possibly, the most important threat to the internal validity of the above results is the extent to which the "parallel trends" assumption stated in equation 1 is valid. One of the standard ways of assessing its plausibility is to use data from the pre-treatment periods to check whether trends were parallel in the past. If this is the case, it is likely that the results achieved here stem from the treatment itself.

ISTAT conducted an earlier university-to-work survey on 1992 graduates, who were interviewed in 1995. ${ }^{31}$ As depicted in Figure 1, prior to 1998 the employment rate dynamics for the control and the treatment groups were remarkably similar. We apply the DID method with linear controls on data for 1992 and 1995 graduates, i.e. before AlmaLaurea come into existence. Table 12 shows that the DID coefficient for unemployment is positive,

\footnotetext{
${ }^{31}$ Unfortunately the 1995 survey does not include data on wages.
} 
Table 11: Effect of AlmaLaurea: the case of Turin and Eastern Piedmont PANEL A

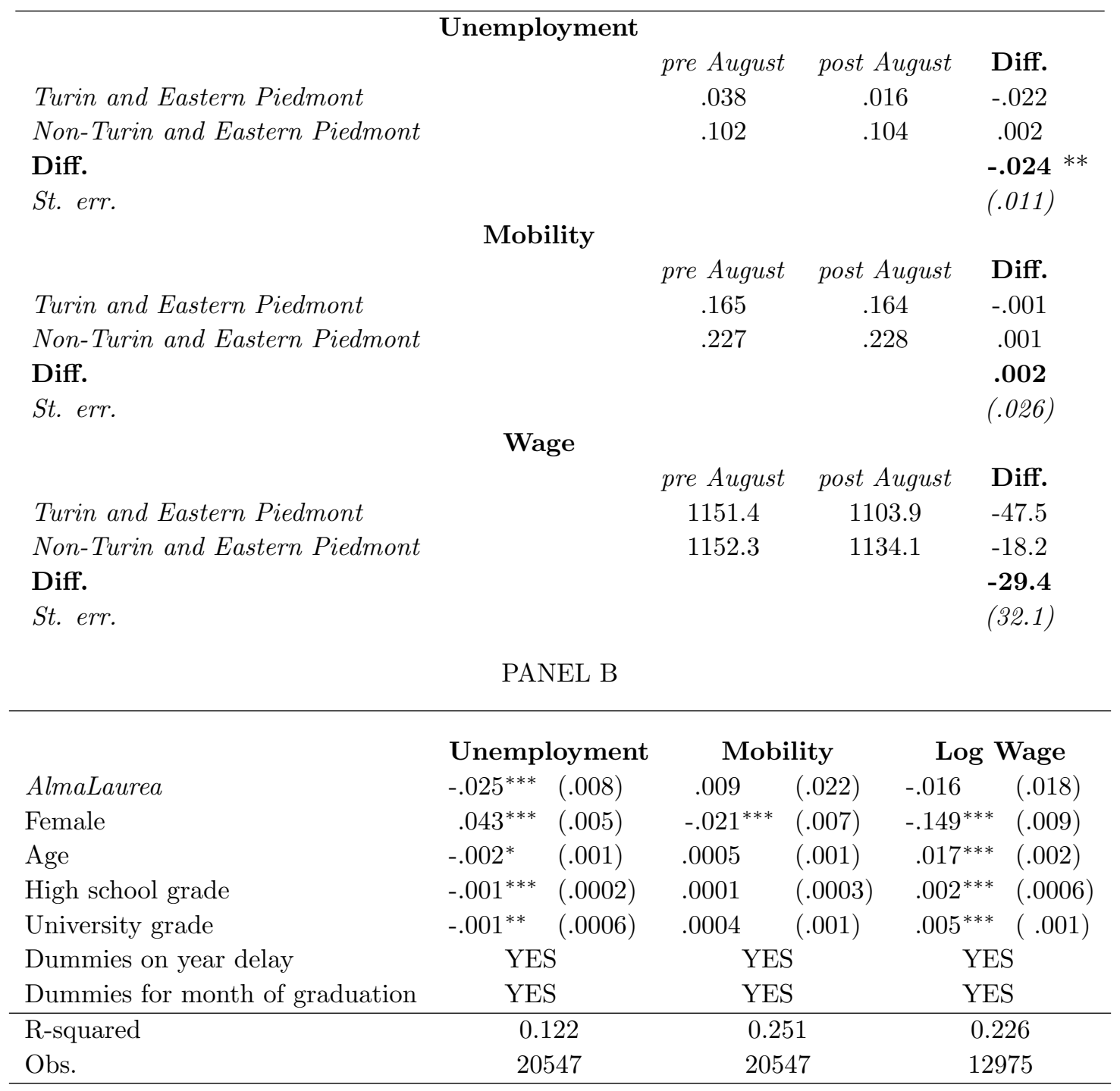

Notes: The analysis is on 1998 graduates. The treatment group is composed of graduates from the Universities of Turin and Eastern Piedmont. Before and after is graduation before and after August. All specifications include university*department fixed effects. Robust Standard Errors in parentheses. All regression are clustered at region*degree*year.

${ }^{*}$ significant at $10 \%{ }^{* *}$ significant at $5 \%{ }^{* * *}$ significant at $1 \%$. 
Table 12: Pre-adoption falsification test of AlmaLaurea

\begin{tabular}{|c|c|c|}
\hline & Unemployment & Mobility \\
\hline AlmaLaurea & $.004 \quad(.013)$ & $.011 \quad(.012)$ \\
\hline 1998 & $-.027^{* * *}(.008)$ & $.005 \quad(.006)$ \\
\hline Female & $.079^{* * *}(.008)$ & $-.026^{* * *}(.005)$ \\
\hline GDP & $-.001^{* *}(.0004)$ & $-.003 \quad(.003)$ \\
\hline Provincial unemployment & $.003 \quad(.002)$ & $.001 \quad(.002)$ \\
\hline R-squared & 0.150 & 0.322 \\
\hline Obs. & 27373 & 27565 \\
\hline
\end{tabular}

Notes: In the first column the dependent variable takes the value 1 if a given graduate is unemployed, and 0 otherwise. In the second column the dependent variable takes the value 1 if a given individual resides in a different region from the one where she attended universities. Only individuals that graduated in 1992 and 1995 are considered. AlmaLaurea takes the value 1 for 1995 graduates from universities that enrol in AlmaLaurea in between 1995 and 1998. All specifications include university*department fixed effects. Robust Standard Errors in parentheses. All regression are clustered at region*degree*year.

* significant at $10 \%{ }^{* *}$ significant at $5 \% ;{ }^{* *}$ significant at $1 \%$.

negligible, and not statistically different from zero. The result is similar for mobility: the AlmaLaurea coefficient is not statistically different from zero. This reduces the likelihood that the coefficients in Tables 8 and 9 stem from unparallel trends in the two groups.

Of course, the above checks do not control for time specific unparallel outcomes. In fact, possible interactions between AlmaLaurea enrolment and unobserved time variant characteristics cannot easily to be ruled out. One could argue, for example, that those universities that self-selected in the treatment group are the ones whose unobservable teaching quality improved most. This might affect the occupational outcomes of their graduates.

To investigate this possibility we build a placebo treatment group composed of graduates from the Universities of Siena and Lecce. According to AlmaLaurea official sources, these universities decided to join AlmaLaurea in 1997, but did not start selling their students' résumés on-line until 1999 and 2003 respectively. If these graduates also experienced an improvement vis-a-vis the others, the likelihood that AlmaLaurea enrolment proxies for something else is higher. We run a regression similar to the one in equation 4, but with graduates from Siena and Lecce as the treatment group and non-AlmaLaurea universities as the control. Table 13 shows that this group experienced a slight increase in unemployment and wages and a decrease in mobility. None of these changes is statistically significantly different from zero. These findings provide evidence against the possibility that enrollment in the treatment group is correlated with unobservables that independently cause employment improvements. 
Fig. 1.- Shares of unemployed graduates

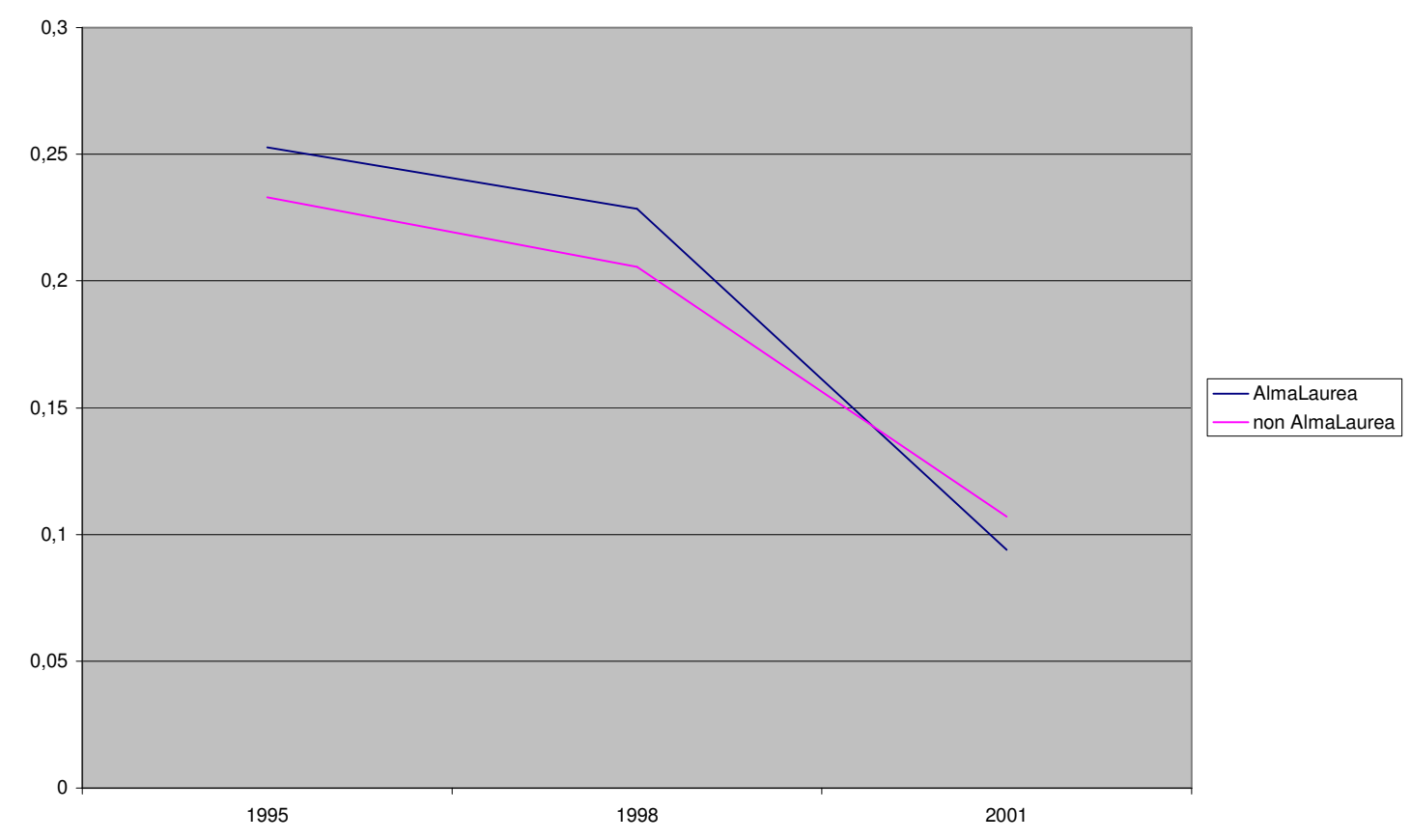

Note: Only graduates from university department that were in the database in 1995 are considered. 
Table 13: Effect of AlmaLaurea using a placebo treatment group

\begin{tabular}{lccc}
\hline \hline & Unemployment & Mobility & Log Wage \\
Placebo AlmaLaurea & .024 & -.017 & .011 \\
& $(.025)$ & $(.026)$ & $(.036)$ \\
\hline R-squared & 0.152 & 0.389 & 0.260 \\
Obs. & 26278 & 26278 & 16464 \\
\hline
\end{tabular}

Notes: Placebo AlmaLaurea takes the value 1 for graduates for 1998 from the Universities of Siena and Lecce, 0 otherwise. All specifications include the full set of controls used in the 4th colums of Tables 8, 9, and 10. Robust Standard Errors in parentheses. All regression are clustered at region*degree* year.

\section{Alternative treatment and control groups and displacement effect}

The DID design can be further strengthened using alternative treatment and comparison groups. In fact, this is likely to reduce the importance of biases or random variation occurring in a single setting (Meyer 1995). In the ideal specification, treatment and control groups should face the same time specific shocks: the more similar the two groups are the better. Given that our dependent variables concern labor market outcomes and that according to our data when the survey took place more than 75 per cent of Italian graduates reside in the region where they attended university (see Table 7 ), a new sample is created including only graduates from regions that include both AlmaLaurea and non-AlmaLaurea universities.

Three Italian regions fit this criterion: Tuscany, Abruzzo, and Sicily. Graduates in these regions represent about 17 percent of the entire population and, within this group, about 57 percent of graduates are in the treatment group universities. As can be seen form Figure 2, AlmaLaurea universities are Florence, Chieti, Catania and Messina. NonAlmaLaurea universities are Pisa, Siena, L'Aquila, Teramo, and Palermo. Table 14 shows that with respect to the general case, in this setting AlmaLaurea has a stronger effect on employment probability (3.5 points) and wages (5 percent) and about the same impact on mobility. The result for wages is not statistically significant. Overall, however, the general results are confirmed and even strengthened.

This control exercise is also helpful for checking for an additional potential problem in our analysis. As mentioned in Section 3, graduates from nearby universities might be used to assess whether there is a displacement effect on non-AlmaLaurea students due to a reallocation of hiring. Interactions are in fact more likely for graduates' occupational outcomes from nearby universities. Hence, for example, the impact of AlmaLaurea might be exaggerated if individuals in the control group were negatively affected by AlmaLaurea itself. For instance, Pisa, in principle, is a better control group for Florence than Bari; nevertheless, 
Fig. 2.- Regions with both AlmaLaurea and Non-AlmaLaurea universities

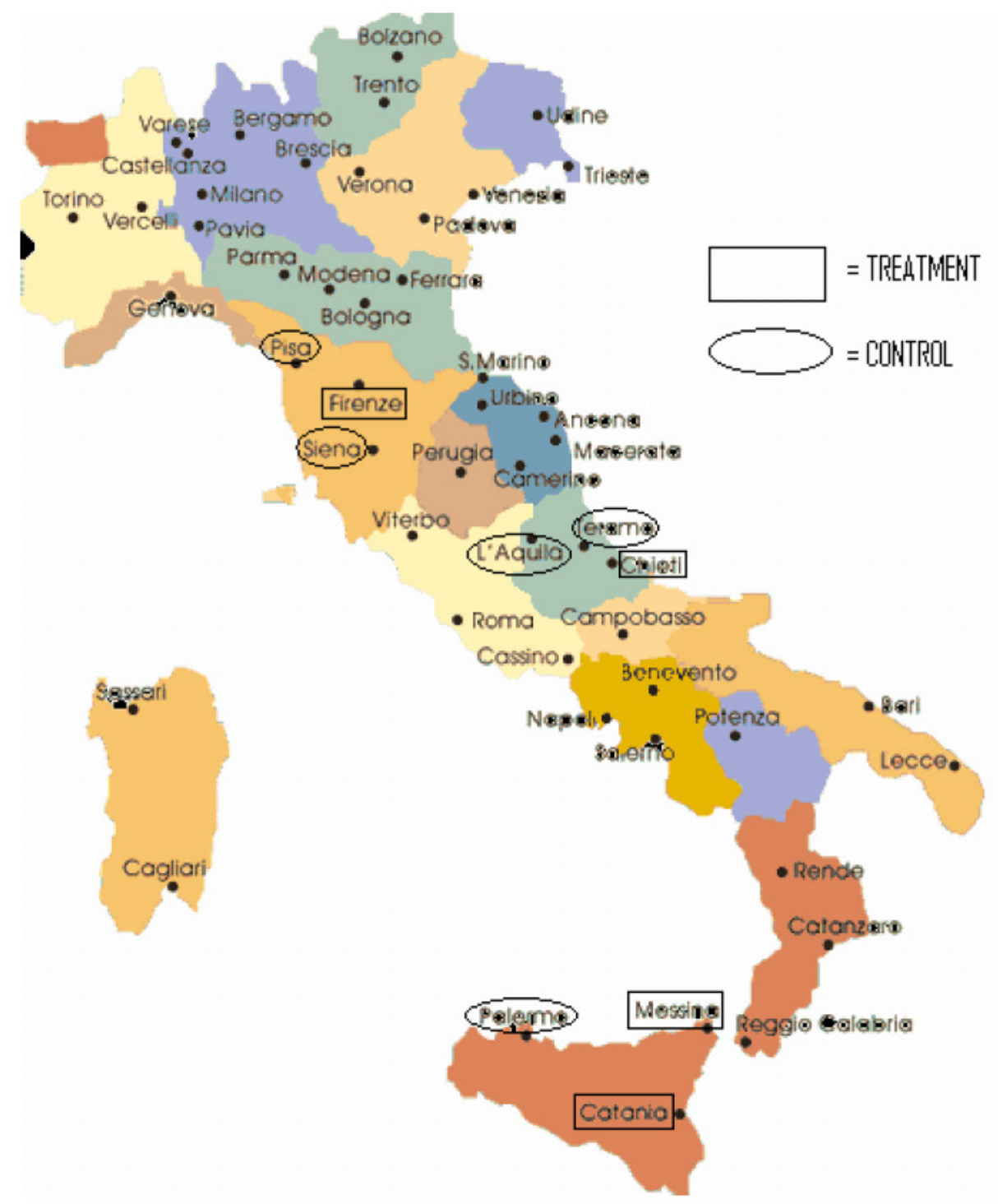


Table 14: Alternative treatment and control groups based on geographic proximity

\begin{tabular}{lccc}
\hline \hline & Unemployment & Mobility & Wage \\
AlmaLaurea & $-.035^{* *}$ & $.024^{*}$ & .053 \\
& $(.017)$ & $(.026)$ & $(.039)$ \\
\hline R-squared & 0.149 & 0.492 & 0.263 \\
Obs. & 6225 & 6225 & 3521 \\
\hline
\end{tabular}

Notes: Only graduates from regions that have both AlmaLaurea and non-AlmaLaurea universities are included. All specifications include the full set of controls used in column 4 of Tables 8, 9, and 10. Robust Standard Errors in parenthesis. All regression are clustered at region*degree*year. ${ }^{*}$ significant at $10 \%{ }^{* *}$ significant at $5 \% ;{ }^{* *}$ significant at $1 \%$.

Table 15: The effect of AlmaLaurea on nearby universities

\begin{tabular}{lccc}
\hline \hline & Unemployment & Mobility & Wage \\
AlmaLaurea & -.008 & .006 & .010 \\
& $(.012)$ & $(.015)$ & $(.023)$ \\
\hline R-squared & 0.152 & 0.295 & 0.260 \\
Obs. & 26436 & 26436 & 16464 \\
\hline
\end{tabular}

Notes: Only individuals that graduated from universities non-AlmaLaurea are included. The variable AlmaLaurea takes the value 1 if a 1998 graduate is awarded a degree from a non-AlmaLaurea university that is located in a region where there are also AlmaLaurea universities, and 0 otherwise. All specifications include the full set of controls in the 4th columns of Tables 8, 9, and 10. Robust Standard Errors in parentheses. All regression are clustered at region*degree* year.

* significant at $10 \%{ }^{* *}$ significant at $5 \% ;{ }^{* * *}$ significant at $1 \%$.

the risk that its graduates' labor market performance is negatively affected by the presence of AlmaLaurea in Florence is higher. To control for this possibility, we perform a DID analysis with non-AlmaLaurea universities in regions where there are AlmaLaurea universities constituting the treatment group, with control group being the remaining non-AlmaLaurea universities. From Table 15, it can be seen that there are no significant differences in the trajectories of the two groups. This suggests that there are no major interactions among the graduates in the two groups and AlmaLaurea does not have negative spillovers on universities located close by.

\section{Conclusions}

Since the late 1990s we have seen a large increase in the importance of on-line labor market intermediaries. While their diffusion may potentially improve labor market functioning increasing the total quantity and quality of matches, solid evidence on their benefits is still missing. In addition, recent works have underlined the possibility of adverse selection 
in the use of electronic intermediaries among the unemployed (Kuhn and Skuterud 2004).

In this article we exploited the exceptional case study provided by the early adoption of the on-line intermediary AlmaLaurea by several Italian universities. The absence of other electronic intermediaries for those universities that had not adopted AlmaLaurea at the time of our study provides us with an adequate control group to estimate the effect of the treatment.

We employed the difference-in-differences method on a repeated cross section data set. Given that enrolment in AlmaLaurea is not random, evaluating its impact is not trivial. However, assuming parallel outcomes between treatment and control group makes our estimation valid. The inclusion of time variant indicators concerning individual and university characteristics and standard tests aimed at ruling out alternative explanations do not raise major concerns in relation to this important assumption.

The evidence shows that the adoption of the on-line labor market intermediary under study improved graduates' labor market outcomes three years after graduation. In particular, according to our most conservative estimate, AlmaLaurea decreased graduates' unemployment probability by about 1.6 percentage points.

Our study also suggests that on-line labor market intermediaries may have a positive effect on matching quality. In fact, in our case study, the wage of graduates from member universities increased by about 3 percent. Finally, we also observe an increase in mobility by about 2.4 percentage points.

The findings of this paper are specific to a given segment of the labor market (i.e. university-to-work transition) and to a peculiar electronic intermediary. Thus, their external validity has to be carefully assessed. In particular, the single characteristic of AlmaLaurea that possibly made it a successful intermediary is also the most unusual: member universities certify the information contained in electronic curricula and also provide some information on the entire population of graduates. This important caveat helps to integrate our findings within the existing literature that does not find any effect of on-line search on the overall unemployment rates and duration (Kuhn and Skuterud 2004; Kroft and Pope 2008).

The results presented in this paper also contribute to the policy discussion on the university-to-work transition. The poor labor performance of Italian graduates has been traditionally ascribed to demand and supply factors. We show that graduate labor market functioning can also be improved by the introduction of on-line intermediaries.

In future research we aim at exploring whether the positive impact of electronic labor market intermediaries affects the whole graduate population evenly. Also, while in this paper 
we focus on average outcomes, the effect on outcome distribution remains an issue for further research.

\section{REFERENCES}

Autor, D.H. (2001). "Wiring the Labor Market." Journal of Economic Perspectives, 15, $25-40$.

Bagues, M., M. Sylos Labini and N. Zinovyeva (2008). "Differential Grading Standards and University Funding: Evidence from Italy." CESifo Economic Studies, Forthcoming.

Burdett, K. and J. Ondrich (1985). "How Changes in Labor Demand Affect Unemployed Workers." Journal of Labor Economics, 3(1), 1-10.

Congressional Budget Office (2002). The Effect of Changes in the Labor Markets on the Natural Rate of Unemployment, April.

Freeman, R.B. (2002). "The Labor Market in the New Information Economy." Oxford Review of Economic Policy, 18(3), 288-305.

Heckman, J.J. (1990). "Varaieties of Selection Bias." American Economic Review, 80(2), Paper and Procedings, 313-318.

Kroft, K. and D.G. Pope (2008). "Does Online Search Crowd Out Traditional Search and Improve Matching Efficiency? Evidence from Craigslist." Mimeo, University of California, Berkeley.

Kuhn, P. (2000). "The Internet and Matching in Labor Markets" in New Economy Handbook. D.C. Jones ed. Amsterdam, Elsevier.

Kuhn, P. and M. Skuterud (2004). "Internet Job Search and Unemployment Duration." American Economic Review, 94(1), 218-232.

Mannheim Centre for European Social Research (2002). "Indicators on School-to-Work Transitions in Europe." Mannheim: Mzes.

Meyer, B.D. (1995). "Natural and Quasi-Experiments in Economics." Journal of Business \&6 Economic Statistics. 13, 151-161.

Pissarides, C. (2000). Equilibrium Unemployment Theory. 2nd Edition. Cambridge MA, The MIT Press. 
OECD (2007). Education at a Glance. Paris, Organization for Economic Co-operation and Development.

Rebick, M.E. (2000). "The Importance of Networks in the Market for University Graduates in Japan: a Longitudinal Analysis of Hiring Patterns." Oxford Economic Papers, 52, 471-496.

Rubin, D.B. (1974). "Estimating Causal Effects of Treatments in Randomized and Nonrandomized Studies." Journal of Educational Psychology, 66, 688-701.

Stevenson, B. (2007). "The Internet and Job Search." Mimeo, University of Pensilvania. 